\title{
A clinical profile of patients with traumatic perforation of tympanic membrane in South Kashmir
}

\begin{abstract}
Objectives: To study various etiologies of tympanic membrane perforation, clinical presentations, management and determine the group who are most likely to benefit from conservative management.

Methods:

Design: Prospective observation study in District Hospital Pulwama.

Participants: 227 patients who had otoscopic evidence of tympanic membrane perforation from May 2016 to May 2017 participated in the study.

Results: Males ( $\mathrm{n}=187$ ) were found to be five times more likely than females (40) to have a traumatic perforation. It affects all groups with highest incidence in second decade of life. Left ear was involved in $182(80 \%)$ patients. The most common cause was assault/slap in $160(70 \%)$. Tinnitus was the most common presenting complaint followed by ear block.178(79\%)patients had grade 1 perforation with a size of less than 30 percent of the entire TM.143(62\%) patients had perforation of posterior quadrant of tympanic membrane. Residual perforation after 3 months was noted in $36(16 \%)$ patients.29 (80\%) patients who had residual perforation had grade 2 or more sized traumatic perforation.
\end{abstract}

Conclusion: The size of perforation may be a significant risk factor in predicting non healing of traumatic perforation.

Keywords: tympanic membrane perforation, risk factors, South Kashmir
Volume 10 Issue 4 - 2018

Dr Irfan UI Shamas

MS ENT and Head and Neck Surgery, India

Correspondence: Irfan UI Shamas, MS ENT and Head and Neck Surgery, ENT Specialist, Srinagar, India, Email drirfan007@gmail.com

Received: August 23, 2017 | Published: July 17, 2018

\section{Introduction}

In our daily ENT practice we come across patients with traumatic rupture of tympanic membrane secondary to either blunt (slap, explosion, rapid descent of aeroplane, deep water diving) or penetrating (ear buds, pencils, syringing for foreign body or wax removal) trauma. The tympanic membrane heals spontaneously in $80 \%$ of cases as per most studies. ${ }^{1}$ The masterly wait and watch policy for 3 months unnecessarily exposes the patients to symptoms of tinnitus, ear block and life style modifications like keeping the ear dry. If we can identify the causes of non healing of traumatic perforation we can intervene surgically at an earlier stage and reduce the morbidity. This paper aims to study various etiologies of traumatic tympanic membrane perforation; evaluate the factors involved in healing of traumatic tympanic membrane perforation; and identify the patients who are unlikely to benefit from conservative management so that early surgical intervention may be recommended.

\section{Methods}

A prospective observational study was conducted in ENT section of District Hospital Pulwama a secondary care hospital in Kashmir from May 2016 to May 2017. The inclusion criterion was a traumatic perforation of the tympanic membrane irrespective of time of presentation. Patients with history of previous ear discharge or impaired hearing, ear surgery or chronic otitis media in the same ear and patients who were lost to follow up were excluded. A total of 227 patients enrolled in this study. After obtaining a history in terms of perforation etiology and duration from occurrence to patient presentation, all patients underwent ENT and general examinations. All the patients were advised to keep their ear dry and follow up regularly every two weeks. All the patients were followed up serially up to three months.

\section{Results}

Two hundred twenty seven (227) participants, 187(82\%) males and $40(18 \%)$ females with a male: female ratio of $4.6: 1$ completed the study. The median age was 19 years with a range of 7-61 years. $102(44 \%)$ belonged to the second decade of life. Left ear was involved in $182(80 \%)$ patients and $45(20 \%)$ patients had traumatic perforation of right ear.

Most (60\%) of the traumatic perforations were due to assault/slap (Chart 1).

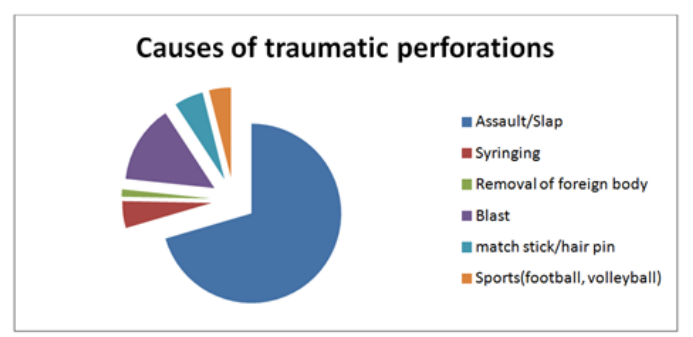


The most common presenting complaint was tinnitus (90\%). Ear block was complained by 185 patients $(84 \%) .17(7 \%)$ patients had bleeding from ear and $5(2 \%)$ patients had vertigo.

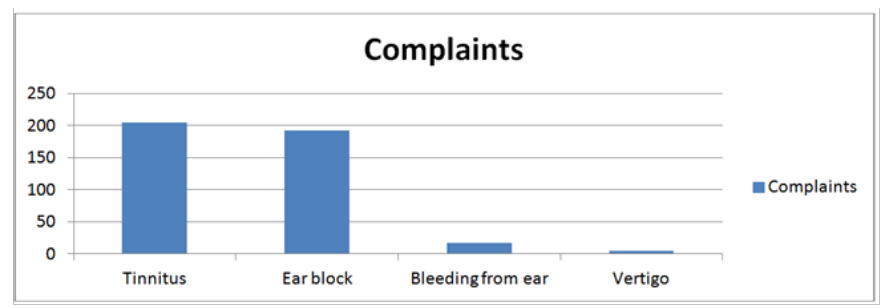

$178(79 \%)$ patients had grade 1 perforation with size not more than thirty percent of the tympanic membrane. 37(16\%) patients had grade 2 perforation with size not more than sixty present. $12(5 \%)$ patients had grade 3 perforation with size more than sixty present (Chart 3 ).

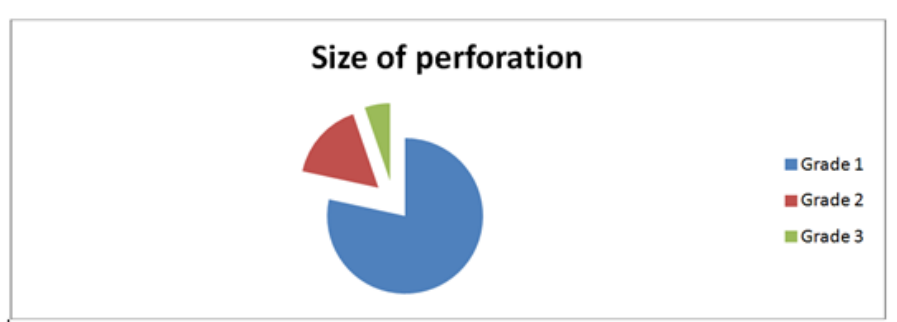

One hundred ninety one (84\%) patients had spontaneous closure of traumatic perforation over a course of 3 months. Thirty six (16\%) patients had residual perforation. Twenty nine $(80 \%)$ patients with residual perforation had grade 2 or more sized traumatic perforation.

\section{Discussion}

The TM is an important component of sound conduction as its vibratory characteristic is necessary for sound transmission in human beings. ${ }^{2}$ Trauma to TM can be caused by over pressure, blunt or penetrating injuries and barotraumas. ${ }^{3,4}$ In this study, over pressure was the most common cause of trauma to TM similar to various studies elsewhere. ${ }^{4,5}$ The current study focused on tympanic membrane perforation as a consequence of trauma. While the management of the otologic complications of trauma is well validated, tympanic membrane perforation has been considered to be mostly a selfhealing condition. Almost all standard textbooks and previous large scale studies consider a 'wait and watch' policy of management for traumatic tympanic membrane perforation. ${ }^{6}$ However, there is still a subset of patients, albeit small, who will not spontaneously heal and tend to suffer increased morbidity for three months. Our study attempts to identify this subset of patients who may benefit from early intervention based on certain risk factors, etiology and characteristics of the perforation.

In this study high ratio of males (82\%) may likely be due to unrest in South Kashmir prevailing during the time of study with $60 \%$ patients having traumatic perforation due to assault/slap. The difference in line with other Indian studies ${ }^{7}$ may be due to peculiar circumstances prevailing in valley due to terrorism/ unrest.
After 3 months of masterly inactivity, almost $84 \%$ of the perforations healed spontaneously. Among the 36 unhealed cases, 12 developed discharge, a marker of increased morbidity. Other studies show similar rates of spontaneous healing. ${ }^{1}$ In this study residual perforations were more likely to occur if the size of perforation was more than grade 2. That larger perforations have fewer chances to heal spontaneously has also been shown by other studies. ${ }^{8-11}$

In conclusion, tympanic membrane perforation size $>30 \%$ may be significant risk factors predicting non-healing of the perforation. Early intervention for those with big perforation may lessen unnecessary morbidity. Bigger multicenter future studies are necessary to confirm these initial findings.

\section{Financial support}

Nill.

\section{Conflict of interest}

There is no conflict of interest.

\section{References}

1. Kristensen S. Spontaneous healing of traumatic tympanic membrane perforations in man: A century of experience. $J$ Laryngol Otol. 1992;106(12):1037-1050.

2. Gacek RR, Gacek MR. Anatomy of the auditory and vestibular systems. In: Snow JB, Ballenger JJ, editors. Ballenger's Otorhinolaryngology Head and Neck Surgery. $16^{\text {th }}$ ed., Vol. 1. Ontario: DC Becker Inc.; 2003. p. 1-5.

3. Mitchell KS. Trauma to the Middle Ear, Inner Ear, and Temporal Bone. Ballenger's Otorhinolaryngology Head and Neck Surgery. $16^{\text {the }}$. Chapter 14. 2003. p. 345-356.

4. da Lilly-Tariah OB, Somefun AO. Traumatic perforation of the tympanic membrane in University of Port Harcourt Teaching Hospital, Port Harcourt. Nigeria. Niger Postgrad Med J. 2007;14(2):121-124.

5. Ologe FE. Traumatic perforation of tympanic membrane in Ilorin Nigeria. Niger J Surg. 2002;8:9-12.

6. Sismanis AA. Tympanoplasty: Tympanic Membrane Repair. In: Gulya AJ, Minor LB, Poe DS (editors). Glasscock-Shambaugh Surgery of the Ear 6th edition. New York: PMPH-USA; 2010. 468 p.

7. Sarojamma, Raj S, Satish HS. A Clinical Study of Traumatic Perforation of Tympanic Membrane. IOSR Journal of Dental and Medical Sciences. 2014;13(4):24-28.

8. Griffin WL. A retrospective study of traumatic tympanic membrane perforations in a clinical practice. Laryngoscope. 1979;89(2 Pt 1): 261282 .

9. Lou ZC, Lou ZH, Zhang QP. Traumatic tympanic membrane perforations: a study of etiology and factors affecting outcome. Am J Otolaryngol. 2012;33(5):549-555.

10. Toner JG, Kerr AG. In Scott-Brown's Otolaryngology. Butterworths Meinemann, London: Otology. $6^{\text {th }}$ ed. In: Booth JB, et al., editors. Ear Trauma. 1997;3:1-3.

11. Orji FT. Non-explosive blast injury of the ear. J Laryngol Otol. 1994;108(5):395-398. 